\title{
Erratum to: Preoperative opioid use and the outcome of thoracoscopic splanchnicectomy in chronic pancreatitis: a systematic review
}

Yama Issa - Usama Ahmed Ali - Stefan A. W. Bouwense • Hjalmar C. van Santvoort • Harry van Goor

Published online: 1 January 2014

(C) Springer Science+Business Media New York 2013

\section{Erratum to: Surg Endosc}

DOI 10.1007/s00464-013-3193-z

The second author's correct first name (given name) is Usama and correct second name (family name) is Ahmed Ali.

The online version of the original article can be found under doi:10.1007/s00464-013-3193-z.

Y. Issa $(\bowtie) \cdot$ U. Ahmed Ali

Department of Surgery, Academic Medical Center,

P.O. Box 22660, 1100 DD Amsterdam, The Netherlands

e-mail: y.issa@amc.uva.nl

U. Ahmed Ali · H. C. van Santvoort

Department of Surgery, University Medical Center Utrecht,

Utrecht, The Netherlands

S. A. W. Bouwense - H. van Goor

Department of Surgery, Radboud University Nijmegen Medical

Center, Nijmegen, The Netherlands 